\title{
EDUCAÇÃO EM CIÊNCIA E EM AUDIOVISUAL: OLHARES PARA A FORMAÇÃO DE LEITORES DE CIÊNCIAS
}

\author{
Mariana Brasil Ramos* \\ Henrique César da Silva*
}

\begin{abstract}
RESUMO: Apresentamos reflexões teóricas pertinentes à formação de leitores de ciências, tomando como exemplo a circulação, incluindo a midiática, e textualizações do tema "mudanças climáticas". As bases teóricas que compõem nossa visão sobre linguagem e ciências e articulam nossa defesa da necessidade de pensar a formação de leitores de ciências simultaneamente à formação em ciências provêm da Análise de Discurso de linha francesa e dos Estudos Sociológicos e Epistemológicos das Ciências. Buscamos compreender o audiovisual nas especificidades discursivas de seu funcionamento como espaço por meio do qual nossos estudantes constroem simultaneamente sentidos para as ciências, para as mudanças climáticas e para o vídeo. Para concluir, afirmamos a importância destes espaços e linguagens nas histórias de leituras dos estudantes e a necessidade de construirmos estratégias de ensino que englobem outras textualizações, no caso, audiovisuais, também como fins educacionais e não apenas como meios.
\end{abstract}

Palavras-chave: Televisão. Mudanças climáticas. Circulação. Textualização. Educação em ciências.

* Departamento de Metodologia de Ensino da Universidade Federal de Santa Catarina (UFSC). Florianópolis (SC) - Brasil.

** Programa de Pós-Graduação em Educação Científica e Tecnológica da Universidade Federal de Santa Catarina (UFSC). Florianópolis (SC) - Brasil.

Contato com os autores: <marianabrasilramos@gmail.com>

Cad. Cedes, Campinas, v. 34, n. 92, p. 51-67, jan.-abr. 2014

Disponível em <http://www.cedes.unicamp.br> 
Educação em ciência e em audiovisual: olhares para a formação de leitores de ciências

\title{
SCIENCE EDUCATION AND AUdIOVISUALS: NOTES ABOUT FORMING SCIENCE READERS
}

\begin{abstract}
We synthesized ideas about the importance of forming Science readers taking, as an example, the circulation of texts related to climate change in the media. The theoretical foundations that compose our vision of language and Science and influence our advocacy of Science readers' formation, along with Science education, comes from the fields of French Discourse Analysis, and of sociological and epistemological studies of Science. We aim to comprehend visual discourses in their specific ways of operation, as a space through which our students simultaneously construct meanings for Science and climate change as well as for the video language. We conclude by stating the importance of these spaces and languages in the students' reading history and the need to create teaching strategies that cover audiovisual texts not only as educational means but also as educational goals.
\end{abstract}

Key words: Television. Climate change. Circulation. Textualization. Science education.

\section{Introdução}

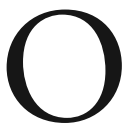

s audiovisuais e o ensino de ciências têm se aproximado nos últimos anos também através da pesquisa. Num levantamento realizado nas atas do Encontro Nacional de Pesquisa em Educação em Ciências (Enpec), Santos e Arroio (2009) observaram um aumento no número de trabalhos com foco temático associado ao uso de audiovisuais, de 13 trabalhos em 1997 para 138, em 2007. Rezende (2008, p. 1) aponta que apesar desta parceria entre ciências e vídeo já ter se consolidado há bastante tempo, os audiovisuais não são usados "para além dos objetivos mais conhecidos, como ilustrar, apresentar e/ou discutir ideias e conceitos científicos”. É possível afirmar que a maioria das pesquisas na área de ensino de ciências posiciona os audiovisuais como recurso didático, estratégia de motivação, de sensibilização, ou problematização inicial. Discutiremos outro objetivo a ser pensado para esta parceria: a formação de leitores de ciências.

No sentido em que a pensamos, a noção de leitura se aplica tanto aos textos verbais, quanto às imagens em movimento e sons no vídeo. Quando nos referimos, portanto, à formação de um leitor de ciências, incluímos a leitura da diversidade de textos nos quais circulam formações discursivas científicas e não científicas, ou referentes científicos. A leitura, tomada como 
acontecimento no domínio do simbólico (ALMEIDA, 2004), pode ser entendida como leitura da televisão, do cinema, da fotografia, da música. E o simbólico é sempre aberto e é, por isso, ao mesmo tempo, administrado. Uma das instâncias onde se dá essa administração do simbólico é o ensino de ciências escolar, que nos produz também como sujeitos-leitores de ciências.

Para pensarmos sobre a formação de leitores de ciências, trabalhamos com três questionamentos fundamentais sobre o modo como as ciências circulam e são lidas em nossa sociedade, apropriado e perpetuado pelas nossas práticas escolares: o primeiro diz respeito à busca de uma leitura única, apenas parafrástica - a um fechamento dos sentidos; o segundo diz respeito ao privilegiamento de certas linguagens - como a verbal - e a uma "naturalização" do olhar para o audiovisual, pois este seria mais "claro" e "óbvio" do que outras linguagens; o terceiro está relacionado ao modo como, habitualmente, não nos aprofundamos em entender de que forma as textualizações são construídas para produzir e administrar os sentidos - trata-se de um olhar para aquém dos referentes, para as formas como estes são enunciados. Para discutir estes três questionamentos, refletimos sobre a textualização e circulação do referente "mudanças climáticas" nos últimos anos.

\section{Mudanças climáticas: circulação e efeitos de leitura}

As mudanças climáticas globais (MC), comumente referidas na mídia sob o termo "aquecimento global" (AG), ocuparam nos últimos anos posição de destaque na televisão, cinema, jornais escritos, internet, rádio e, entre outros, nas escolas. Exemplo desta circulação foi a inserção nas escolas do estado de São Paulo de uma proposta de ensino sobre MC em 2007, através de materiais e metodologias previamente selecionados e distribuídos pela Secretaria de Estado da Educaçãao ${ }^{1}$ para utilização nas aulas de Apoio à Continuidade de Estudos (espaço que visava ao trabalho de eixos temáticos de maneira interdisciplinar no ensino médio da rede estadual). Estes compreendiam textos provenientes do Guia do Estudante Abril, ${ }^{2}$ exercícios de vestibulares de anos anteriores e o filme Uma verdade inconveniente (UMA VERDADE, 2006), protagonizado pelo ex-vice-presidente norte-americano Al Gore. ${ }^{3}$ Destacamos a seguir as sugestões destinadas ao trabalho dos professores da área de Ciências Humanas, para a abordagem do filme em sala de aula:

Sensibilização: Propomos inicialmente que os professores das distintas áreas se organizem para projetar o documentário - Uma verdade 
Educação em ciência e em audiovisual: olhares para a formação de leitores de ciências

inconveniente. Nele, o ambientalista Al Gore, ex-vice-presidente dos EUA, apresenta uma de suas palestras e faz uma advertência sobre o futuro de nosso planeta e da nossa civilização, ao revelar e apresentar estudos que comprovam que o superaquecimento global é um perigo real e imediato. O vídeo dará condições de se ampliar o estudo em diferentes perspectivas e será objeto de sensibilização importante para desencadear discussões futuras em sala de aula. (SÃO PAULO, 2008, p. 3 , grifos nossos)

Este trecho compõe as regularidades de um panorama midiático sobre MC: no caso, o próprio material didático legitima os discursos audiovisuais construídos pelo ambientalista $\mathrm{Al}$ Gore, introduzindo-os a partir dos verbos "revelar", "apresentar" e "comprovar", remetendo estes discursos aos efeitos de univocidade e inequivocidade sobre o tema, implicitamente científicos: é possível ler uma elipse do adjetivo "científico" ao lado da palavra "estudos".

Enunciados de catástrofe climática foram recorrentes em materiais sobre $\mathrm{MC},{ }^{4}$ favorecendo uma leitura que aceita o discurso do AG como verdade e, mais que isso, como verdade científica. As imagens contribuem para construir estas leituras sobre o tema: o urso polar que fica preso em pequenos blocos de gelo devido ao derretimento das calotas do Ártico se transformou em emblema, ao se dizer algo imageticamente relacionado às MC. Quedas de blocos que compõem as geleiras, secas, furacões e, até mesmo, tsunamis e terremotos constituem memórias discursivas imagéticas sobre AG. Algumas destas imagens são exploradas neste filme, bem como nos materiais destinados aos estudantes da rede estadual de São Paulo.

As imagens, fotográficas e audiovisuais, sugerem maior credibilidade aos enunciados verbais e posicionam o leitor diante destes fatos, ao estabelecerem ligação com outras imagens conhecidas, pela TV, de dramas humanos como as enchentes. As imagens da TV, dos materiais didáticos, nesse sentido, significam o aquecimento global para estes leitores. Essa ideia está relacionada ao próprio modo como consideramos as imagens em nossa sociedade, reforçado por práticas presentes na educação escolar: como se elas recortassem o real de maneira neutra, como se não houvesse escolhas neste recorte, como se não dependessem das histórias de leitura dos sujeitos que as constroem e que as leem, construindo, ao mesmo tempo, um discurso delas e sobre elas. Nesse sentido, compreendemos que

[...] a leitura (interpretação) de imagens integra-se numa história que é maior do que nós, num processo do qual não somos a origem; uma imagem, 
ao ser lida, insere-se numa rede de imagens já vistas, já produzidas, que compõem a nossa cotidianidade, a nossa sensação de realidade diante do mundo. A leitura (interpretação) de imagens não depende apenas do contexto imediato da relação entre leitor e imagem: para lê-la o leitor se envolve num processo de leitura (interpretação) que já está iniciado. (SILVA, 2006, p. 77)

Quando olhamos uma imagem, há uma diversidade de interpretações possíveis. Contudo, ao olharmos o urso no bloco de gelo, nós o significamos em relação às MC porque estas leituras já vêm sendo construídas anteriormente, nos anúncios publicitários, em outros filmes, em telejornais, em fotografias na internet (e também na escola, que se apropria destes discursos para falar de...), que instituem uma memória, um modo de leitura histórico desta imagem. Se pararmos para refletir, por que um urso polar em um bloco de gelo nos lembraria de MC? Ou mesmo: o que há para além das quatro margens destas fotografias de ursos polares?

Temos a impressão de que não há nada após estas margens, pois esta relação com a imagem nos é apagada, pela forma como aprendemos a ler e considerar as imagens em nossa sociedade, inclusive através do ensino escolar. ${ }^{5}$ Por exemplo, a própria construção textual destinada aos professores da rede de ensino de São Paulo dirige a leitura sobre o filme, não apenas considerando seus conteúdos, mas também o que o filme, enquanto versão, significa: "Nele, o ambientalista Al Gore, ex-vice-presidente dos EUA, apresenta uma de suas palestras". É como se o vídeo não se constituísse discurso em seus outros elementos que não o protagonista-orador. Outros elementos que provocam, eles mesmos, efeitos de leitura, efeitos de realidade, por ser exatamente linguagem audiovisual, e não outro discurso - um paper, um livro didático, uma matéria escrita em um jornal; ou que não estivessem em jogo as seleções de cenas, as imagens, os ângulos, a escolha das frases: o vídeo é reduzido ao que o protagonista apresenta.

A explicitação deste efeito é muito importante, quando situado dentro de um conjunto de leituras sobre o vídeo em nossa sociedade, que o coloca como "recorte do real" (quando pensamos em documentários ou telejornais, por exemplo), ou como "prova concreta" de algo (quando pensamos em sua utilização para incriminar ou absolver alguém que foi filmado durante um assalto). Este modo de ler o vídeo também o significa: sua legitimidade ao dizer influencia também o modo como lemos a construção do referente (aquilo de que se fala). Bruzzo (1998) discute um efeito de leitura decorrente do modo como vemos os documentários, apontando que a separação 
entre estes e os filmes de ficção consolidou a ideia de que ao documentário atribui-se a enunciação da verdade.

A ideia do documentário como verdade já vem sendo abordada no âmbito do ensino de ciências, inclusive tendo este último certa "responsabilidade histórica” na construção deste efeito de leitura dos documentários, em especial, os "educativos" ou "científicos". Rezende e Struchiner (2009) resgatam uma série de recomendações, no contexto brasileiro, para a produção de vídeos educativos que, entre outras características: prezam pela clareza e objetividade, pela voz do mestre (narrador em off) que aponta o que o leitor deve observar/ouvir/compreender, ou seja, primam por um controle dos sentidos, relacionados aos conteúdos científicos e sua exatidão na aprendizagem. Trata-se de uma abordagem que prevalece nas escolas brasileiras como um modelo de inserção dos vídeos em sala de aula.

O filme Uma verdade inconveniente (2006), recomendado pela Secretaria de Educação, também parece reforçar o caráter de realidade do referente, ${ }^{6}$ pois ele é constituído de elementos audiovisuais que nos remetem ao documentário científico: um narrador onipresente, onisciente; a construção de uma história "real" deste narrador-personagem; a apresentação comparativa de imagens (filmadas ou fotografadas) e gráficos sobre o tema; a convocação/menção de diversos especialistas como fonte de credibilidade; o verbalismo (sempre há uma voz que nos explica o que devemos ver); o excesso de cortes. Há também elementos que primam pela atenção do espectador, mas que também podem ser relacionados aos documentários, inclusive como tendência mais atual: a dramaticidade (associada inclusive à própria trilha musical), as imagens espetaculares da natureza, a construção de uma história "pessoal" como forma de abordagem do tema - características que remetem o documentário ao entretenimento e que visam à atenção e envolvimento emocional do leitor.

Identificamos, na diversidade de discursos circulantes sobre MC, um direcionamento da leitura de modelos, tanto climáticos, quanto econômicos e sociais: simplificaçóes de processos (apagamentos de outros discursos) funcionam no sentido de fortalecer algumas representações sobre o AG, como esta sequência causal e linear: o AG é um fato causado pelo aumento de gás carbônico na atmosfera, causado pela poluição humana, causada pelos nossos modos de vida. Uma visão que, ao culpar "cada um", impossibilita que culpemos, por exemplo, uma nação. Simplificação, no sentido de uma busca de esclarecimento, ou de tornar o texto "mais inteligível" para um 
público heterogêneo, é característica marcante da TV atual, consistente com uma ideia de "educação" ou "ensino" que se relaciona ao controle da leitura em direção a um sentido único. Assim, quanto mais eficaz este controle, melhor funcionaria a "aprendizagem" através do vídeo.

Estas memórias sobre o tema MC não são questionadas como leituras possíveis, mas têm como efeito a impressão de que se trata "da" leitura, porque assim foi "dito" pelo vídeo. Mas, quem disse? Os cientistas disseram? Que sentidos? Seriam eles uma voz uníssona? Ainda, disseram a partir de que argumentos, de que maneira de interpretar a realidade? Todos os cientistas interpretam a realidade da mesma maneira? Na televisão? A TV disse? O professor disse? Na escola? O ex-vice-presidente dos Estados Unidos? Mas como isso foi dito? O que não foi dito? Por quais estratégias nos fazem ler o que lemos? Quais seriam, talvez, as condiçôes imediatas de produção destas leituras? E as condições mais amplas? - que remetem aos imaginários sobre ciências, sobre audiovisuais, sobre documentários, sobre MC? Enfim, quando pensamos em textos audiovisuais, quais são as estratégias de administração dos sentidos? Como a escola contribui, ou não, para este controle?

Tratando-se de dizeres que remetem às ciências e que, portanto, só têm validade de verdade dentro de condições bem definidas e explicitadas, o que temos nessa grande circulação de discursos de MC é o apagamento dessas condições de produção dos textos, o apagamento de que os sentidos das ciências só são válidos dentro de certas perspectivas e que jamais são únicos. O silenciamento destas questôes, no que diz respeito à formação escolar de estudantes de ciências, está atrelado ao modo de se conceber os discursos da TV, da escola e das ciências: quando são pensadas as relações entre estes três espaços, instituições significantes e seus respectivos textos produzidos e reciprocamente circulantes, em geral, desconsideram-se suas condições de produção de textos, de leituras, de leitores e de realidades.

\section{Condições de produção de leitura das ciências}

Se retornarmos ao enunciado extraído do material desenvolvido pela Secretaria para o trabalho dos professores com os estudantes sobre o tema MC, teremos um exemplo de como as ideias de leitura do audiovisual vêm sendo desenvolvidas na escola: as atenções recaem sobre o que o vídeo diz, como forma de suscitar estudos futuros sobre o referente, mas em nenhum momento neste material podemos observar menções sobre "como". Como 
Educação em ciência e em audiovisual: olhares para a formação de leitores de ciências

o vídeo constrói ideias sobre $\mathrm{MC}$ ? Como as imagens são utilizadas para remeter a alguns sentidos? Quem são os atores? Como se fala das MC? A partir destas questôes, podemos dizer que o filme, neste material escolar, é visto como um "meio" para que os professores e estudantes se apropriem do referente, mas não como um fim para que os mesmos se apropriem da linguagem audiovisual e de como ela faz parte da construção deste referente.

O controle dos sentidos sobre/dos discursos científicos pelo apagamento de suas condições de produção aparece desde a nossa formação inicial como professores de ciências. Esta formação, por sua vez, está relacionada ao modo como os cientistas (que foram nossos professores) se tornam cientistas, através de processos de iniciação que visam à manutenção das estruturas em jogo nas práticas científicas, ou sua formação para a ciência normal, nos termos de Thomas Kuhn. E isso tem a ver com a textualização das ciências na forma de manuais para a formação dos cientistas (KUHN, 1979).

Dessa formação, também dos licenciandos, derivam-se certas representações de ciências que, ao apagar sua historicidade, corroboram a formação de imaginário que compreende a busca de um único sentido, de uma única leitura: "A Ciência”. Isto, como prática discursiva, materializa-se no uso da linguagem pelas ciências, no modo como é significada a leitura através desse discurso das ciências:

Já na ciência, a busca é por uma interpretação única. Ou seja, os cientistas esperam que suas teorias forneçam a interpretação de determinados fenômenos e, para tal, procuram formulá-las na linguagem que melhor se coadune a esse intento. [...] É de se esperar que o posicionamento da ciência como instituição tenha consequências sobre o seu ensino. (ALMEIDA et al., 2006, p. 62-63)

Como ressaltam estes autores, parte desses processos tem lugar em nossas instâncias formais e não formais de ensino das ciências: seja nas escolas, nos livros didáticos, nas revistas de divulgação, entre outros. Ao mesmo tempo, como percebemos, por exemplo, em situações de controvérsias científicas em evidência (NELKIN, 1989), estas formações discursivas científicas não são uma, não são homogêneas. Essa versão das ciências - A Ciência -, nesse sentido de univocidade, produz, também, modos de leitura.

Embora os discursos científicos visem à univocidade e inequivocidade, ambas são impossíveis e a polissemia e a heterogeneidade enunciativa também fazem parte da ciência. No caso de MC, são perceptíveis vários 
apagamentos dessa polissemia, pelo modo como certos enunciados, também científicos, circularam com menos frequência, ou receberam inúmeras críticas quando circularam. ${ }^{7}$

Silva e Boveloni (2009) mostraram, por exemplo, como a significação geocientífica de mudança climática global está apagada em livros didáticos de Ciências e Geografia para o ensino fundamental no Brasil, em função de uma midiatização desses temas, caracterizada, entre outros aspectos, pela visão de causalidade linear, não complexa, não sistêmica e de catastrofismo antropogênico. ${ }^{8}$

Apontamentos como o de Almeida et al. (2006) lembram que a tendência ao controle, que caracteriza o discurso científico, apesar de sua impossibilidade total, pode contribuir no espaço escolar para o apagamento da polissemia que também caracteriza esse discurso e sua produção, formulação e circulação, levando a práticas de leitura onde predominam repetições empíricas e formais (ORLANDI, 1998). Ou seja: busca-se apagar os gestos de interpretação dos leitores. As práticas de leitura de repetições empíricas e formais são aquelas regidas pelo pressuposto inconsciente de que um sentido emana do texto, bastando-se ler para "captá-lo".

Se já existe, nas práticas escolares, uma tendência a privilegiar-se apenas a leitura parafrástica, "que se caracteriza pelo reconhecimento (reprodução de um sentido que se supóe ser do texto, dado pelo autor)" (ORLANDI, 1998, p. 12), o que dizer dos discursos científicos dentro das escolas? Estes que, desde sua transposição para os manuais, buscam esse modelo de leitura? E mais: que através dele, provoca-se certos efeitos de leitura em relação ao modo com que lemos as ciências como "A Ciência", ou à imagem de cientista. Trata-se de retomar a não unicidade de leituras na escola, num mesmo movimento de retomada da não unicidade de leituras nas ciências e da não homogeneidade na circulação dos discursos da ciência. E isso, supomos neste trabalho, pode envolver trabalhar os meios, no caso a TV, também como fins.

\section{A forma e a formação de leitores de ciências}

Nas últimas décadas, são mais frequentes pesquisas que, ao invés de se aterem apenas aos conteúdos científicos (no sentido estrito do termo, ou seja, estancarem no estabilizado), buscam resgatar a polissemia constitutiva dos processos de leitura entre os estudantes de ciências, para trabalhar, aí sim, contrariando seu apagamento, as condições de validade ${ }^{9}$ que permitem 
Educação em ciência e em audiovisual: olhares para a formação de leitores de ciências

aos enunciados serem identificados como pertencentes a uma formação discursiva científica ou não (RICON; ALMEIDA, 1991; SILVA, 2004; SOUZA; ALMEIDA, 2005; MICHINEL; BURNHAM, 2007). Alguns destes trabalhos buscam modificar as relações de estudantes e professores com os textos e, portanto, com a leitura das ciências.

No entanto, a problematização da questão da leitura no ensino de ciências na escola pode ganhar mais um passo, se introduzirmos a questão da textualização. Um deslocamento para a textualização (SILVA, 2010) implica não apenas modificar as situações de controle da leitura escolar - para que outros sentidos que não os esperados sejam "permitidos" e possam ser trabalhados -, mas que o próprio texto deixe de ser apenas meio para produção de sentidos, ainda que agora abertos, e passe a ser também fim.

O vídeo, a textualidade audiovisual, nem sempre é objeto de estudo. O objeto é "a Ciência”, a leitura e escrita desta, que já estão pressupostas, se o estudante for "alfabetizado". Há pesquisadores da área que se voltam para a leitura da linguagem audiovisual, como Oliveira Jr. (2004), Bruzzo (1998), Amorim (2006) e Guimarães e Silva (2009), entre outros. Destes trabalhos pode-se derivar, ainda que implicitamente, subsídios para trabalhar o vídeo como objeto de ensino e não apenas como meio. Rezende (2008, p. 2), ao debater sobre o uso de audiovisuais para o ensino de História das Ciências, nos lembra que "já há uma compreensão consensual de que tanto os filmes de ficção quanto os documentários são produções, e não testemunhos diretos e neutros da história de 'como as coisas ocorreram'”, observação que pode ser pensada para qualquer narrativa sobre as coisas, não apenas no sentido de reconstituição, mas de construção de materialidade textual.

Ainda assim, é possível identificar a suposição de que a escola seria privilegiada numa transposição dos discursos científicos que seriam verdadeiros, e a TV, entre outros modos de circulação, não. Para nós, interessa pensar todas estas textualizações como versões, possibilitando, além de uma ampliação do universo simbólico dos leitores de ciências que desejamos formar, sua expressão.

A relação do aluno com o universo simbólico não se dá apenas por uma via - a verbal -, ele opera com todas as formas de linguagem na sua relação com o mundo. Se considerarmos a linguagem não apenas como transmissão de informação, mas como mediadora (transformadora) entre o homem e sua realidade natural e social, a leitura deve ser considerada no seu aspecto mais consequente, que não é de mera decodificação, mas da compreensão. (ORLANDI, 1998, p. 38) 
Propomos a leitura do referente no texto, ou seja, a "realidade" como referente de um texto; a ideia da formação de um sujeito-leitor tanto de ciências, quanto de televisão, cinema, ou jornal. Isso porque não há como separar, dentro dos processos de significação, o "conteúdo" da "forma”, ou a simultaneidade do referente no texto. Há, sim, uma ilusão desta separação: um esquecimento.

Pensando que todos os discursos podem ser tomados como possíveis formas de construção de sentidos por parte de quem os lê (PÊCHEUX, 1990), filiamo-nos à ideia, já presente na literatura da área, de mudança de um modelo de ensino de ciências que enfatiza a construção de um sentido único na leitura textual e privilegia o texto escrito ou oral, para outro que vislumbre, além da polissemia característica da leitura, também a pluralidade de formas textuais que permeiam nossa cultura contemporânea, na qual os discursos científicos têm grande circulação. E a televisão é uma das diferentes formas textuais (assim como o rádio, a internet, os jornais impressos, as falas de um professor, as revistas de divulgação, os livros, didáticos ou não, o cinema, entre outras), através das quais entramos em contato com discursos sobre/das ciências naturais. E é, entre os diversos textos, o mais presente na vida dos brasileiros.

Não supomos que, por esta grande penetração, a TV esteja sozinha nos processos de leitura e circulação das ciências. Entendemos que, exatamente por fazer parte destes processos, ela poderia ser mais aprofundada no ensino formal, pois, assim como - ou mais que - a escola, a TV intervém constitutivamente no imaginário que situa um sujeito do discurso em relação às ciências (ALTHIER-REVUZ, 1998).

Dizer das ciências na TV, mostrar um cientista na TV, falar em nome "Da", tudo isso também funciona num processo de significação da própria televisão: ao mesmo tempo em que a TV legitima, pois dá voz, constrói as ciências para os telespectadores, esta passa a ser considerada mais crível, pois "mostra" um cientista, recorre a uma "fonte segura", que ela mesma transformou em segura, transformou em passível de ser considerada como importante.

Na mesma medida, os discursos científicos constroem a televisão, dentro e fora dela: fora, por exemplo, na escola, quando um professor de ciências (tomado como inscrito nas formações discursivas científicas) utiliza um texto audiovisual como "ilustração" da sua aula, aí são movimentados sentidos de credibilidade (por exemplo, sobre um documentário em detrimento de um 
vídeo de ficção); quando um professor pergunta “o que o vídeo quis dizer?”, são movimentados sentidos sobre a leitura dos textos audiovisuais; quando um professor "mostra" um processo celular em um vídeo, movimenta sentidos sobre a "realidade" do texto audiovisual; quando um cientista diz que sua entrevista foi distorcida para ir ao ar na TV, também imprime aí uma relação com este espaço. Dentro, ao trazer um espetáculo de imagens científicas, convidando o leitor a se interessar por seu discurso; ao exibir as "últimas novidades da ciência", movimentando sentidos de pertencimento do leitor (pela TV) a este mundo de novidades.

É lugar comum, atualmente, dizer de se desenvolver a criticidade dos estudantes em relação às ciências; dizer de contribuir para uma leitura crítica por parte dos estudantes de ciências. No entanto, qual o significado de ser crítico, ler criticamente, se, ao final da aula de ciências, quando avaliado, o estudante deve reproduzir aqueles sentidos desejados pelo professor? Se esta avaliação situa-se apenas no domínio da escrita? Se, a pluralidade de sentidos, a polissemia não é valorizada? Se a diversidade de linguagens é pouco considerada? Estas perguntas apontam para a necessidade de se desenvolver estratégias de ensino que busquem, ao contrário, formar um leitor de ciências que supere inteligibilidade e interpretação, ${ }^{10}$ um leitor que compreenda os discursos científicos, no sentido colocado por Orlandi (1998, p. 115): "o compreensível: é a atribuição de sentidos considerando o processo de significação no contexto de situação, colocando-se em relação enunciado/enunciação". Ou, ainda, numa leitura pensada dentro do contexto do ensino de ciências:

O inteligível diz respeito apenas à decodificação, ao reconhecimento do signo. $\mathrm{O}$ interpretável diz respeito à atribuição de sentidos, o que se produz na ilusão da aderência entre texto e sentido, como se o sentido estivesse lá. Já o compreensível implica em saber que o sentido pode ser outro, em restituir o caráter de versão do texto em relação ao discurso, ou seja, considerar suas condições de produção. A compreensão, portanto, de textos que remetem às ciências, diferentemente da sua simples interpretação, diz respeito à compreensão da produção das ciências em seu contexto social. (SILVA, 2010, p. 39)

E essa "compreensão da ciência em seu contexto social" passa pelo modo como ela circula, pelos meios e processos que a fazem circular de determinadas maneiras, produzindo determinados efeitos e isso tem a ver com os modos como essa circulação se textualiza. Na nossa sociedade, atualmente, a televisão 
é parte fundamental desses processos. Sendo a escola um lugar privilegiado do ponto de vista do contato com os estudantes, seria interessante pensar o ensino das posições ocupadas pelas ciências dentro dos diversos textos que nos bombardeiam diariamente, bem como não menosprezar estas leituras das MC da televisão. Como manter no esquecimento e não problematizar outros discursos, aqueles não privilegiados pela mídia, ou pela escola? Como não discutir a própria TV como textualização legítima da circulação dos discursos científicos?

\section{Considerações finais}

Concluímos com a reafirmação da importância de um espaço para outras linguagens, como as audiovisuais, nas histórias de leituras dos estudantes de ciências e a necessidade de construirmos estratégias de ensino que englobem estas textualizações também como fins educacionais e não apenas como meios.

Trata-se de buscar formas de trazer os textos também para o primeiro plano do ensino, aquele plano em que atua a ilusão de ser puro conteúdo. Talvez tarefa grande para um professor de ciências sozinho. Talvez melhor em diálogo com outros. Talvez melhor se em sua formação houver experiências de leituras das ciências pelas mídias que trabalhem também as próprias mídias.

Enfim, encerramos este trabalho com a certeza de muitos caminhos ainda a percorrer, a construir, a discutir, herdeiros que somos de uma cultura que parece ter se esforçado para esquecer que toda verdade (estas que hoje já sabemos serem provisórias, construídas, históricas e produtos de uma cultura), para ser uma verdade como tal e não outra, precisa ser dita (escrita, filmada, fotografada, desenhada) e precisa circular; dizeres, dos quais aqui focamos o audiovisual; dizeres e circulação que fazem parte dos modos como nos constituímos ao lidarmos com estas verdades. Talvez, o desafio resida em se retrabalhar essa memória...

\section{Notas}

1. Disponível em: <http://www.rededosaber.sp.gov.br/portais/programaapoio/Home/Temas/ AquecimentoGlobal/tabid/885/language/pt-BR/Default.aspx>. Acesso em: 2 maio 2013.

2. Disponível em: <http://www.rededosaber.sp.gov.br/portais/Portals/33/arquivos/CHT_\%20 ApoioContEstudos.pdf/>. Acesso em: 22 abr. 2013. 
Educação em ciência e em audiovisual: olhares para a formação de leitores de ciências

3. Prêmio Nobel da Paz em 2007, junto com o Intergovernmental Panel on Climate Change (IPCC), da ONU.

4. Esse tipo de discurso catastrofista não é tão recente, embora nos últimos dez anos tenha ganhado maior amplitude. Cf., por exemplo, editorial da Science de janeiro de 1967, em que o editor previa que a temperatura atmosférica terrestre teria um aumento de $4^{\circ} \mathrm{C}$ até o ano 2000 se a concentração de CO2 na atmosfera continuasse aumentando (ABELSON, 1967).

5. É importante lembrar que esta relação de apagamento não é exclusiva das textualizações imagéticas. A leitura e a escrita, em nossas escolas, também são pensadas desta forma.

6. No sentido de correspondência inequívoca.

7. Para citar dois exemplos, confira a entrevista do geógrafo Aziz Ab'Saber em entrevista à Folha de S. Paulo, em 2007, no Jornal da Ciência, de 15 de março de 2007. Disponível em: <http:// www.jornaldaciencia.org.br/Detalhe.jsp?id=45316 >. Acesso em: 20 abr. 2012; e a entrevista do biólogo alemão Joseph Reichholf à revista Época em 2009.

8. Formação discursiva que envolve enunciados como "O homem está acabando com o mundo", "O homem está acabando com a vida na Terra".

9. A ideia de que há vários sentidos possíveis não pode ser confundida com a ideia de que qualquer sentido é possível, pois há determinação histórica; nem com a ideia de que todos os sentidos são válidos, pois há discursos, como os da ciência, em que operam condições de validade para os sentidos como parte de suas condições de produção, o que não acontece em todos os discursos.

10. Perspectiva em que se inserem as práticas de leitura mais tradicionais nas aulas de ciências.

\section{Referências}

ABELSON, P.H. Global weather. Science, New York, v. 155, n. 3.759, p. 153, jan. 1967.

ALMEIDA, M.J.P.M. Discursos da ciência e da escola. Campinas: Mercado das Letras, 2004.

ALMEIDA, M.J.P.M. et al. Perguntas, respostas e comentários dos estudantes como estratégia na produção de sentidos em sala de aula. In: NARDI, R.; ALMEIDA, M.J.P.M. (Org.). Analogias, leituras e modelos no ensino da ciência - a sala de aula em estudo. São Paulo: Escrituras, 2006. p. 61-65.

AMORIM, A.C.R. Nos limiares de pensar o mundo como representação. Pro-Posiçōes, Campinas, v. 17, n. 1, (49), p.177-194, jan./abr. 2006. Disponível em: <http://www.proposicoes.fe.unicamp.br/ $\sim$ proposicoes/textos/49_ dossie_amorimac.pdf>. Acesso em: 23 abr. 2013. 
AUTHIER-REVUZ, J. A encenação da comunicação no discurso de divulgação científica. In: AUTHIER-REVUZ, J. Palavras incertas: as não coincidências do dizer. Campinas: Editora da Unicamp, 1998. p. 107131.

BRUZZO, C. O documentário em sala de aula. Ciência \& Ensino, Piracicaba, n. 4, p. 23-25, jun. 1998.

GUIMARÃES, L.B.; SILVA, B.L. Planejamentos de ensino entremeando biologia e cultura. Ensino em Re-Vista, Uberlândia, v. 16 n. 1, p. 33-45, jan./dez. 2009. Disponível em: <http://www.gpef.fe.usp.br/teses/agenda_2011_03. pdf>. Acesso em: $1^{\circ}$ maio 2013.

KUHN, T.S. A função do dogma na investigação científica. In: DEUS, J.D. (Org.). A crítica da ciência. 2. ed. Rio de Janeiro: Zahar, 1979. p. 53-80.

MICHINEL, J.L.; BURNHAM, T.F. A socialização do conhecimento científico: um estudo numa perspectiva discursiva. Investigaçôes em Ensino de Ciências, Porto Alegre, v. 12, n. 3, s.p., 2007. Disponível em: <http:// www.if.ufrgs.br/public/ensino/vol12/n3/v12_n3_a5.htm>. Acesso em: 23 abr. 2012.

NELKIN, D. Controversy: politics of technical decisions. 2. ed. Londres: Sage Publications, 1989.

OLIVEIRA JR., W.M. Perguntas à televisão e às aulas de geografia: crítica e credibilidade nas narrativas da realidade atual. In: PONTUSCHKA, N.; OLIVEIRA, A.V. (Org.). Geografia em perspectiva: ensino e pesquisa. 2. ed. São Paulo: Contexto, 2004. p. 353-365.

ORLANDI, E.P. Discurso e leitura. São Paulo: Cortez; Campinas: Editora da Unicamp, 1998.

PÊCHEUX, M. O discurso: estrutura ou acontecimento. Campinas: Pontes. 1990.

REZENDE, L.A. História das ciências no ensino de ciências: contribuições dos recursos audiovisuais. Ciências em Tela, Rio de Janeiro, v. 1, n. 2, p. 1-7. 2008. Disponível em: <http://www.cienciaemtela.nutes.ufrj.br/ artigos/0208rezende.pdf>. Acesso em: $1^{\circ}$ maio 2013.

REZENDE, L.A.; STRUCHINER, M. Uma proposta pedagógica para 
Educação em ciência e em audiovisual: olhares para a formação de leitores de ciências

produção e utilização de materiais audiovisuais no ensino de ciências: análise de um vídeo sobre entomologia. Alexandria: Revista de Educação em Ciência e Tecnologia, Florianópolis, v. 2, n. 1, p. 45-66, mar. 2009. Disponível em: <http://alexandria.ppgect.ufsc.br/files/2012/03/LuizAugusto. pdf>. Acesso em: 22 abr. 2013.

RICON, A.E.; ALMEIDA, M.J.P.M. Ensino da física e leitura. Leitura: Teoria \& Prática, Campinas, ano 10, n. 18, p.7-16, 1991.

SANTOS, P.C.; ARROIO, A. A utilização de recursos audiovisuais no ensino de ciências: tendências nos Enpecs entre 1997 e 2007. In: ENCONTRO NACIONAL DE PESQUISA EM EDUCAÇÃO EM CIÊNCIAS, 12. Anais... Florianópolis: Abrapec, 2009. p. 1-12.

SÃO PAULO (Estado). Secretaria da Educação. Apoio à continuidade de estudos: Dossiê Aquecimento Global. São Paulo: SEE-SP, 2008. 15p. Disponível em: <http://www.rededosaber.sp.gov.br/portais/Portals/33/ arquivos/CHT_\%20ApoioContEstudos.pdf >. Acesso em: 20 abr. 2012.

SILVA, H.C. A noção de textualização para pensar os textos e as práticas de leituras da ciência na escola. In: PINTO, G.A. (Org.). Divulgação cientifica e práticas educativas. Curitiba: CRV, 2010. p. 25-42.

SILVA, H.C. Lendo imagens na educação científica: construção e realidade. Pro-Posiçôes, Campinas, v. 17, n. 1 (49), p. 71-83, jan.-abr. 2006.

SILVA, H.C. Discursos e leituras da física na escola - uma abordagem introdutória da síntese newtoniana para o ensino médio. Brasília, DF: Universa, 2004 .

SILVA, H.C.; BOVELONI, D.C. Los temas cambios climáticos y calentamiento global en los libros de texto: la falta de la mirada geológica. Enseñanza de las Ciencias de la Tierra, Girona, v. 17, p. 7, 2009.

SOUZA, S.C.; ALMEIDA, M.J.P.M. Escrita no ensino de ciências: autores do ensino fundamental. Ciência \& Educação, Bauru, v. 11, n. 3, p. 367382, 2005. Disponível em: <http://www.scielo.br/scielo.php?script=sci_ arttext\&pid $=$ S1516-73132005000300003\&lng=en\&nrm=iso $>$. Acesso em: 20 abr. 2013.

UMA VERDADE Inconveniente. Título original: An inconvenient truth. Direção: Davis Guggenheim. Intérprete: Al Gore. Produção: Al Gore. 
Roteiro: Lawrence Bender, Scott Burns, Laurie Lennard e Scott Z. Burns. 2006. 1 DVD (100min).

Recebido em 12 de maio de 2013.

Aprovado em 11 de outubro de 2013. 